Check for updates

Cite this: RSC Adv., 2018, 8, 22737

Received 14th April 2018

Accepted 14th June 2018

DOI: $10.1039 / c 8 r a 03205 j$

rsc.li/rsc-advances

\title{
Characteristics of negative DC discharge in a wire- cylinder configuration under coal pyrolysis gas components at high temperatures
}

\author{
Quanlin Chen, (D) Mengxiang Fang, (D) Jianmeng Cen* and Jiajia Liu
}

\begin{abstract}
This work aims to provide a comprehensive understanding of negative DC discharge under coal pyrolysis gas components $\left(\mathrm{CO}_{2}, \mathrm{H}_{2}, \mathrm{~N}_{2}, \mathrm{CH}_{4}, \mathrm{CO}\right)$ and air. The characteristics of negative DC discharge were studied in a wire-cylinder configuration at an ambient temperature range of $20-600{ }^{\circ} \mathrm{C}$ by analyzing $V-I$ characteristics, discharge photographs, and gas composition. With increasing temperature, corona onset voltage, spark breakdown voltage and operational voltage range for corona discharge decrease, but discharge current and electron current ratio increase. Discharge current of $\mathrm{CO}_{2}$ is higher than that of air due to the difference of electronegativity. During $\mathrm{CO}_{2}$ discharge, with the increase of output voltage, three types of discharge are successively observed, namely corona, glow and arc. However, during $\mathrm{H}_{2}$ discharge, only glow discharge is observed. Temperatures significantly affect the capability of $\mathrm{CO}$ to attach electrons. The discharge characteristic of $\mathrm{CO}$ is similar to the electronegative gas media at $20^{\circ} \mathrm{C}$ and the non-electronegative gas media when the temperature exceeds $350^{\circ} \mathrm{C}$. Chemical reactions and carbon generation are observed during the $\mathrm{CH}_{4}$ and $\mathrm{CO}$ discharge process. The product of carbon filaments under the $\mathrm{CH}_{4}$ gas medium leads to discharge current volatility and short circuit. These results assist in understanding the property of ESP at high temperatures.
\end{abstract}

\section{Introduction}

High-temperature gas cleaning is a key challenge for advanced power generation technologies, such as pressurized fluidized bed combustion and integrated gasification combined cycle., ${ }^{1,2}$ Hightemperature particle removal technologies include hightemperature cyclone separators, ceramic filters, granular filters, and high-temperature electrostatic precipitators (ESP). The advantages of a cyclone separator include having a simple structure and stable operation, but the fine particle collection efficiency is low and can only be used as a pretreatment. ${ }^{3}$ Ceramic filter exhibits high particle removal efficiency but can be broken at high temperature because of thermal shock explosion. ${ }^{4}$ The pressure drop and energy consumption for the granular filter are relatively high, besides, granular materials are difficult to regenerate at high temperature. ${ }^{5}$ The ESP has the advantages of high particle removal efficiency, low pressure decrease, and wide adaptability; it is widely used in coal-fired power plants at temperatures less than $150{ }^{\circ} \mathrm{C}^{6}$ However, research on the property of ESP at temperatures above $350{ }^{\circ} \mathrm{C}$ is limited.

Corona discharge is a fundamental process for ESP, because the ions produced in this process play an important role in particle charging, thereby affecting particle collection efficiency. $^{7-14}$ Xiao $^{15}$ studied the characteristics of DC negative

State Key Laboratory of Clean Energy Utilization, Zhejiang University, Hangzhou 310027, P. R. China. E-mail: jmcen@zju.edu.cn corona discharge in a wire-cylinder configuration at an ambient temperature range of $350-850{ }^{\circ} \mathrm{C}$ and concluded that the ratio of the electron current to the total discharging current increases with increasing temperature. Because of the electron current, the maximum collection efficiency decreases and energy consumption increases as temperature increases. ${ }^{16} \mathrm{Xu}^{3}$ studied the relationship of applied voltage and collection efficiency, and concluded that both onset and spark voltages decreased with an increase in temperature and resulted in a decrease in particle collection efficiency. To solve this problem, Yan $^{\mathbf{6}, 10}$ studied the effect of discharge device structure on operation voltage range and concluded that the operating voltage range increases with increasing discharge gap, and the ribbon electrodes produce sparks more easily compared with the wire and spiral electrodes. In addition to temperature and discharge device structure, gas media are also an important factor affecting the discharge characteristics. Wang ${ }^{\mathbf{1 5 , 1 7}}$ studied the discharge characteristics at high temperatures in the atmosphere of $\mathrm{O}_{2}$, $\mathrm{CO}_{2}$, and $\mathrm{N}_{2}$ and concluded that the discharge current in the mixture of $\mathrm{CO}_{2}$ and $\mathrm{N}_{2}$ gas media increases when the content of $\mathrm{CO}_{2}$ increases.

The main components of coal pyrolysis gas are $\mathrm{CO}_{2}, \mathrm{H}_{2}, \mathrm{~N}_{2}$, $\mathrm{CH}_{4}$, and CO. ${ }^{1}$ Gas media are an important factor that influences discharge characteristics. However, there is almost no research on discharge characteristics under coal pyrolysis gas media. Thus, this work investigates characteristics of negative DC discharge in a wire-cylinder configuration under coal 
pyrolysis gas media at high temperatures, thereby assisting in the understanding of the property of ESP at high temperatures.

\section{Experimental setup}

The schematic of the experimental system is shown in Fig. 1. The system consists of five parts, namely, gas cylinders, a high voltage power supply, a wire-cylinder negative DC discharge configuration, a temperature-controlled furnace, and a measurement system.

\subsection{Discharge device}

The wire-cylinder discharging device is placed on the middle of the corundum tube, which is heated by the furnace. The length of the corundum tube is $1.2 \mathrm{~m}$ and its inner diameter is $74 \mathrm{~mm}$. The stainless sleeve tube is connected with the corundum tube using flanges. The outer diameter of the stainless sleeve tube is identical to the inner diameter of the corundum tube.

The wire-cylinder discharge configuration consists of a discharge electrode and a cylinder electrode, which was made of stainless steel 310s. The effective length of the discharge electrode is $180 \mathrm{~mm}$, and the diameter is $2 \mathrm{~mm}$. The anode is a stainless tube with a length of $180 \mathrm{~mm}$ and an inner diameter of $60 \mathrm{~mm}$. Thus, the inter-electrode gap of this discharging device is $29 \mathrm{~mm}$. The effective discharge electrode is the part of the cathode wire within the cylinder.

At high temperature, the insulation performance of insulating materials decreases. Therefore, in this work, a polytetrafluoroethylene plate is placed on the sleeve tube flanges, through which two holes are cut to allow the anode and cathode conducting wires to traverse without connecting.

\subsection{Electric circuit}

The high voltage power supply provides an adjustable DC negative voltage of $0-60 \mathrm{kV}$ and a maximum output current of $20 \mathrm{~mA}$. In this work, the voltage supplied by a high voltage power supply is called output voltage, and the voltage between the anode and the cathode is called the port voltage, which is measured by a high voltage probe and Agilent 34970 A data acquisition. Port voltages are the real voltages between the anode and cathode, thus they are widely used to present the results of discharge characteristics. An $800 \mathrm{k} \Omega$

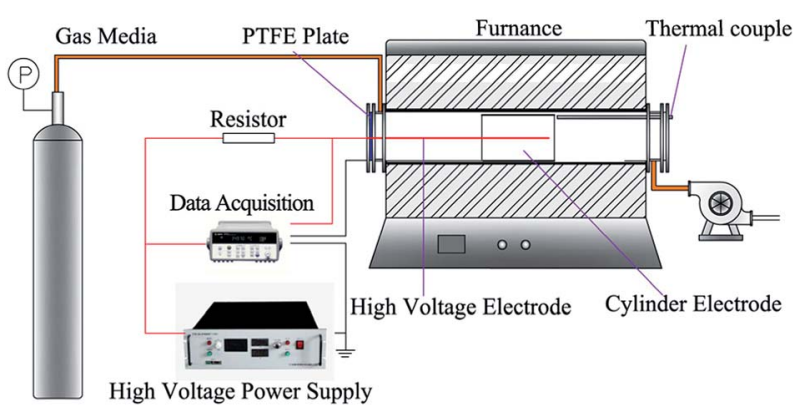

Fig. 1 Schematic of the experimental setup. resistor is used to protect the power supply when spark breakdown occurs. Electric current is measured through the Agilent 34970A data acquisition with the minimum accuracy of $1 \mathrm{nA}$.

\subsection{Temperature measure and control}

The silicon molybdenum electric heating elements, which are connected to the programmable temperature controller, heat the corundum tube. An S-type thermocouple is used to measure the temperature of the furnace, which is then fed back to the programmable temperature controller to adjust the heating power of the electric heating elements.

There is a large temperature difference inside and outside the corundum tube, and the temperature has great influence on the discharge characteristics. Thus, in this work, a K-type thermocouple is stuck into the corundum tube through the stainless steel sleeve to measure the temperature of the discharging device and gas media. The K-type thermocouple does not contact with the corundum tube, so the temperature measured by the thermocouple mainly comes from the convective heat transfer of the gas and the radiative heat transfer of the corundum tube. The gas flow rate is $100 \mathrm{~L} \mathrm{~h}^{-1}$ and the diameter of corundum tube is $74 \mathrm{~mm}$, thus the airflow velocity is about $0.006 \mathrm{~m} \mathrm{~s}^{-1}$ at room temperature. The length of the corundum tube is $1.2 \mathrm{~m}$ and the discharge device is placed on the middle of corundum tube. Therefore, the heating time is about $30-100 \mathrm{~s}$, enough to heat the gas to the set temperature.

\subsection{Experimental procedure}

The gas flow rate is adjusted to $100 \mathrm{~L} \mathrm{~h}^{-1}$ by using a flow meter, and the pressure in the furnace is maintained at $1 \mathrm{~atm}$. The gas media used in the experiments are the main components of coal pyrolysis gas, namely, $\mathrm{CO}_{2}, \mathrm{H}_{2}, \mathrm{~N}_{2}, \mathrm{CH}_{4}$, and $\mathrm{CO}$. Air is also investigated in this work for comparison with other gas media. The testing temperatures on each gas media are set at room temperature $\left(20^{\circ} \mathrm{C}\right)$ and high temperatures set from $350{ }^{\circ} \mathrm{C}$ to $600{ }^{\circ} \mathrm{C}$ at $50{ }^{\circ} \mathrm{C}$ interval. The furnace temperature is increased at a rate of $3-5{ }^{\circ} \mathrm{C}$ per minute after setting a program and pressing the start key. Simultaneously, the gas tank valve is opened, and the gas flow is allowed into the furnace. Then, the negative high voltage power supply is started, and the output voltage is adjusted when the temperature has reached the setting value. The corona onset voltage is determined when the first corona occurred. The corona current is detected and recorded once the corona is set, and the output voltage is increased by intervals of 1 or $0.5 \mathrm{kV}$. The spark voltage is determined when the discharge current increased sharply. Glow discharges, instead of corona discharges, are occurred under non-electronegative gas media. The threshold voltage is determined when the first glow occurred. Each test condition is maintained for $5 \mathrm{~min}$ to record the results. Certain tests are repeated to check the repeatability of the experimental data. The results highlight the good performance of the experimental system. 


\section{Result and discussion}

\subsection{Effect of temperature}

3.1.1 Effect of temperature on corona onset/spark voltages. Fig. 2 shows the corona onset and spark breakdown voltages at different temperatures under $\mathrm{CO}_{2}$ gas medium. As the temperature increases, the corona onset voltage and spark breakdown voltage decrease. With the increase of temperature, the Townsend ionization coefficient increases, resulting in the non-selfsustained discharge more easily converted to self-sustained discharge, which is the onset of corona. ${ }^{18}$ As the temperature increases from $20{ }^{\circ} \mathrm{C}$ to $600{ }^{\circ} \mathrm{C}$, the corona onset voltage decreases from $8 \mathrm{kV}$ to $3.2 \mathrm{kV}$, while the spark breakdown voltage decreases from $16.5 \mathrm{kV}$ to $8.88 \mathrm{kV}$. Thus, the operational voltage range for corona discharge decreases from $8.5 \mathrm{kV}$ to 5.68 $\mathrm{kV}$ as the temperature increases from $20^{\circ} \mathrm{C}$ to $600^{\circ} \mathrm{C}$. Too small operation voltage range for corona discharge will result in frequent breakdown of electrostatic precipitator and affect its stable operation.

Fig. 3 compares the theoretical corona onset voltages with the experimental data at different temperatures. The theoretical corona onset voltage is calculated through Peek's formula as expressed in eqn (1).

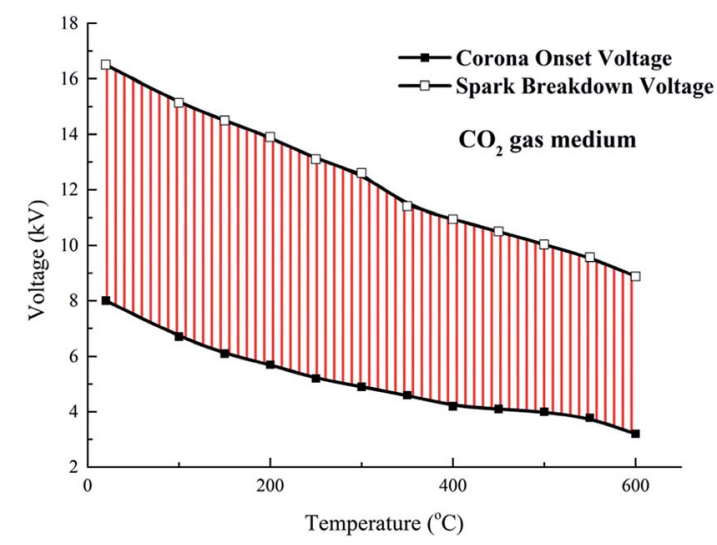

Fig. 2 Effect of temperature on corona onset and spark voltages.

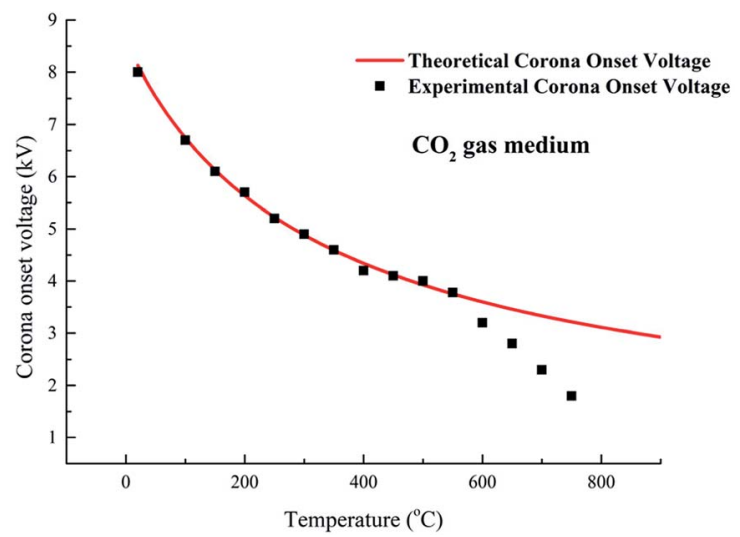

Fig. 3 Experimental corona onset voltages and Peek's formula at different temperatures.

$$
E_{0}=3.1 \times 10^{6} \times \delta \times f \times\left(1+\frac{0.0308}{\sqrt{\delta \times r_{0}}}\right),
$$

where $E_{0}$ is the electric field at the $r_{0}$ radius, representing the minimum electric field required to excite the corona discharge; $\delta$ is the relative density which is determined by eqn (2); and $f$ is the factor, which defines the smooth degree of a cathode's surface when it is perfectly polished $(f=1) ; f$ can be low according to the roughness of the cathode's surface. In this work, $f=0.28$.

$$
\delta=\frac{M_{\mathrm{gas}}}{M_{\mathrm{air}}} \times \frac{P \times T_{0}}{P_{0} \times T}
$$

where $M$ is relative molecular mass; $P_{0}=10325 \mathrm{~Pa}, T_{0}=$ $298 \mathrm{~K}$.

The experimental onset voltages match well with the theoretical onset voltage at relatively low temperature (equal or below $550{ }^{\circ} \mathrm{C}$ ). However, the experimental onset voltage is apparently lower than the theoretical onset voltage at a relatively high temperature (equal or above $600{ }^{\circ} \mathrm{C}$ ). At $600{ }^{\circ} \mathrm{C}$, the experimental onset voltage is $3.2 \mathrm{kV}$, while the theoretical onset voltage is $3.6 \mathrm{kV}$. Similarly, $\mathrm{Xiao}^{15}$ and $\mathrm{Yan}^{6}$ reported the difference between theoretical and experimental onset voltage at high temperatures. These results show that Peek's formula suits other electronegative gas media well by adjusting relative density, although this formula is induced from air gas medium. The deviation that occurred at high temperature can be attributed to Peek's formula being determined at room temperature, where the discharge current is mainly composed of ion currents, while the electron current plays an important role on discharge current at high temperature.

3.1.2 Effect of temperature on $V-I$ characteristics and discussion on current compositions at high temperature. Fig. 4 illustrates the $V-I$ characteristics of the wire-cylinder configuration at temperatures ranging from $350{ }^{\circ} \mathrm{C}$ to $600{ }^{\circ} \mathrm{C}$ in the $\mathrm{CO}_{2}$ gas medium. The discharge current increases when the temperature increases. At the port voltage of $8 \mathrm{kV}$, the discharge current increases from $188 \mu \mathrm{A}$ at $350{ }^{\circ} \mathrm{C}$ to $445 \mu \mathrm{A}$ at $600^{\circ} \mathrm{C}$. As shown in eqn (3) and (4), the Townsend first ionization coefficient $\alpha$ means the number of pairs of electrons produced by inelastic collision between an electron and a neutral gas from

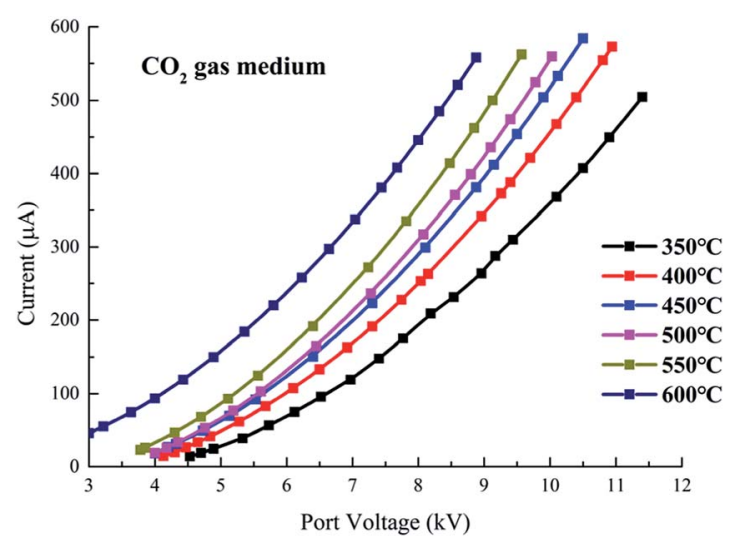

Fig. 4 Effect of temperature on $V-I$ characteristics. 
a cathode to an anode. With the increase of $\alpha$, the discharge current increases sharply. An increased temperature enlarges the mean free path of the electrons and gas molecules and helps electrons gain additional energy from the imposed electric field. Therefore, the possibility of inelastic collisions between the electrons and gas molecules increases, and additional electronpositive ion pairs are produced, thus causing a high discharge current at high temperatures. ${ }^{7}$

$$
\begin{gathered}
i=\frac{i_{0} \exp (\alpha d)}{1-\gamma(\exp (\alpha d)-1)}, \\
\alpha=\frac{1}{\lambda} \exp \left(-V_{i} / E \lambda\right),
\end{gathered}
$$

where $i$ is discharge current, $i_{0}$ is the residual current when gas is not discharged, $\alpha$ is the Townsend first ionization coefficient, $d$ is the distance between anode and cathode, $\gamma$ is the Townsend third ionization coefficient, $\lambda$ is the mean free path, $V_{\mathrm{i}}$ is ionization potential, $E$ is the electric field.

Temperature affects not only the ionization process but also the electron attachment process. According to Christophorou, ${ }^{24}$ with the increase of temperature, the non-dissociative attachment efficiency decreases, while the dissociative attachment efficiency increases. For gas medium such as $\mathrm{CO}_{2}$ which attach electrons both non-dissociative and dissociative, the attachment efficiency first decreases and then increases with the temperature increasing. However, compared to the influence of temperature on ionization, the influence on attachment can be neglected. ${ }^{11}$

Fig. 5 compares the calculated saturation unipolar ion currents with the experimental corona currents at different temperatures. According to Sigmond, ${ }^{\mathbf{1 9}}$ the saturation unipolar ion density is expressed in eqn (5). Thus, the maximum possible unipolar ion current at a given port voltage $U_{\mathrm{P}}$ and a wirecylinder configuration are provided in eqn (6).

$$
\begin{gathered}
\rho_{\mathrm{s}}=\frac{\varepsilon_{0}}{\mu t}, \\
I_{\mathrm{s}}=\frac{4 \pi l \varepsilon_{0} \mu U_{p}{ }^{2}}{R^{2}\left[\ln \left(R / r_{0}\right)\right]^{2}},
\end{gathered}
$$

where $\rho_{\mathrm{s}}$ is the saturation unipolar ion density, $I_{\mathrm{S}}$ is the saturation unipolar ion current, $\mu$ is the mobility of negative ions, and $t$ is the ion drift time, denoting the time required for an ion drift from the cathode to the anode.

Ion mobility is assumed to be independent of the electric field. It is a function of the relative density. For negative ions, the mobility is $2.7 \times 10^{-4} / \delta \mathrm{m}^{2} \mathrm{v}^{-1} \mathrm{~s}^{-1}$.

At $20{ }^{\circ} \mathrm{C}$, the experimental currents are smaller than the corresponding saturation ion currents when the port voltage is below $12.58 \mathrm{kV}$, thus indicating the absence of electron-carried currents. When the port voltage exceeds $12.6 \mathrm{kV}$ at $20{ }^{\circ} \mathrm{C}$, the experimental corona currents exceed the corresponding saturation ion currents. At $400{ }^{\circ} \mathrm{C}$ the corona currents are higher than the saturation ion currents when the port voltage is above $5 \mathrm{kV}$. These results indicate that the electron currents cannot be ignores in these cases, and the discharge currents comprise ion
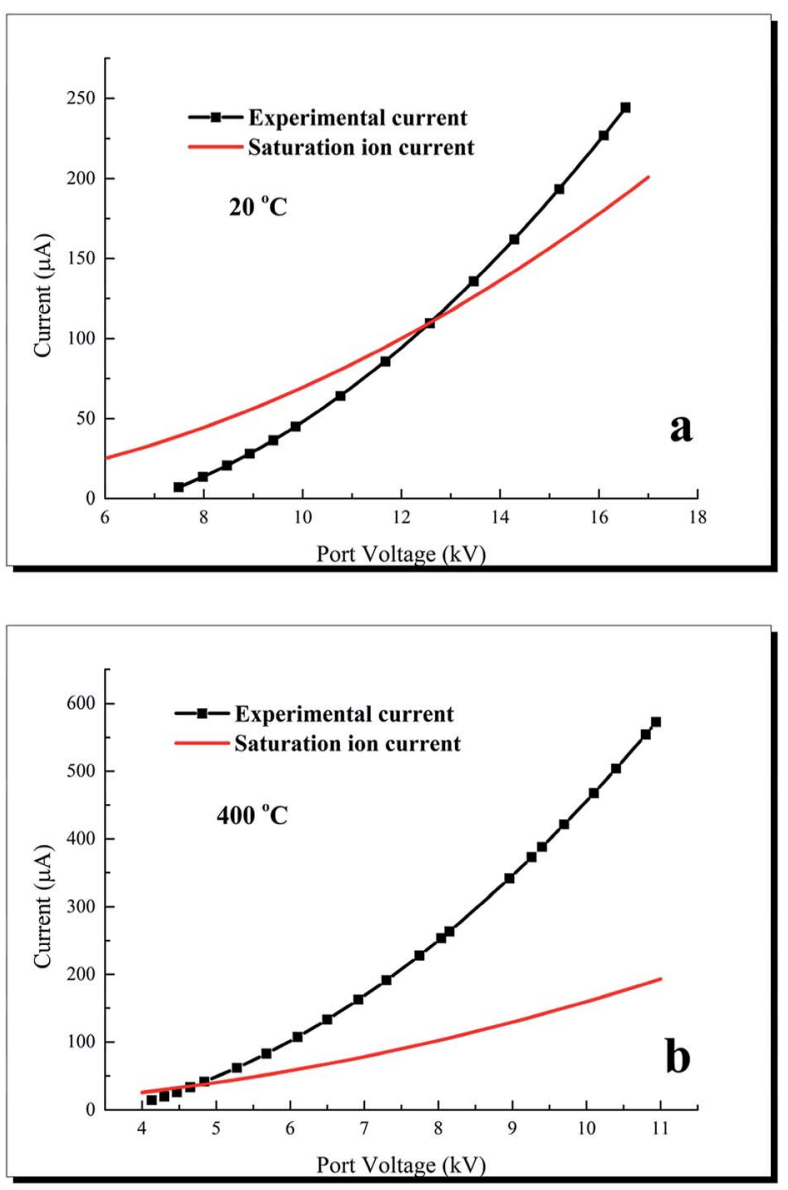

Fig. 5 Comparison of experimental corona current and saturation ion current at different temperatures.

currents and electron currents. The electron current $I_{\mathrm{e}}$ can be calculated through $I-I_{\mathrm{s}}$. The electron current ratio, which means the proportion of electron current in the total current, can be calculated through $I_{\mathrm{e}} / I$. On the port voltage of $10 \mathrm{kV}$, discharge current at $20{ }^{\circ} \mathrm{C}$ is $48 \mu \mathrm{A}$ while the corresponding saturation ion current is $69.5 \mu \mathrm{A}$, thus, the electron current ratio $\left(I_{\mathrm{e}} / I\right)$ is 0 . When the temperature increases to $400{ }^{\circ} \mathrm{C}$ and the port voltage remains $10 \mathrm{kV}$, discharge current is $457 \mu \mathrm{A}$ while the corresponding saturation ion current is $159.7 \mu \mathrm{A}$, thus the electron current ratio is 0.65 . These results indicate that electron current ratio increases as temperature increases. Yan ${ }^{6}$ and $\mathrm{XiaO}^{11,17}$ also found the existence of electron current, and the reason is that the ionization coefficient increases with the increases of temperature, while the attachment effect is basically unchanged. Electron current not only exists in the process of high temperature discharge, but also occurs in the discharge process of short inter-electrode distance. Ferreira ${ }^{25}$ established a point-to-plane discharge device and reported the existence of electron current when the distance below $1.5 \mathrm{~cm}$.

In the process of electrostatic precipitation, dust particles are charged through the collision with charged ions, and move to the dust collecting plate under the action of electric field force. Therefore, ion current is important for dust charging. The existence of electron current only increases energy 
consumption but cannot improve the efficiency of dust removal. Thus, reducing the proportion of electronic current is conducive to improving the efficiency of dust removal and reducing energy consumption.

\subsection{Effect of gas media}

3.2.1 Effect of gas media on $V-I$ characteristics and corona onset/spark voltages under different electronegative gas media. The corona onset voltage and spark breakdown voltage $v s$. increasing ambient temperature in different atmospheres are shown in Fig. 6. The corona onset voltage in $\mathrm{CO}_{2}$ atmosphere is higher than that in air, and the difference decreases with increasing temperature. At $350{ }^{\circ} \mathrm{C}$, the corona onset voltage of $\mathrm{CO}_{2}$ is $4.6 \mathrm{kV}$, and that of air is $4 \mathrm{kV}$, thus the difference between them is $0.6 \mathrm{kV}$. When the temperature increases to $600{ }^{\circ} \mathrm{C}$, the corona onset voltage of $\mathrm{CO}_{2}$ is only $0.1 \mathrm{kV}$ greater than that of air. It can be obtained from the Peek formula that the corona voltage increases with the relative density increasing, and the relative molecule mass of $\mathrm{CO}_{2}$ is greater than the air, so the corona voltage in $\mathrm{CO}_{2}$ is higher than that in air, which is in accordance with the experimental results.

The spark breakdown voltage of $\mathrm{CO}_{2}$ atmosphere is constantly higher than that of air atmosphere at the ambient temperature of 350-600 ${ }^{\circ} \mathrm{C}$, as shown in Fig. 6(b). However, Xiao ${ }^{11}$ reported that the spark breakdown voltage of air is higher than that of $\mathrm{CO}_{2}$, because the attachment ability of air to electrons is stronger than that of $\mathrm{CO}_{2}$. The glow discharge is usually formed after the gas breakdown. According to the glow discharge theory, the glow discharge is caused by the secondary emission of the cathode, and the higher the ionization potential of gas media, the more easily the glow discharge is produced, that is, it is easier to breakdown. The ionization potential for $\mathrm{CO}_{2}, \mathrm{O}_{2}$ and $\mathrm{N}_{2}$ are $13.3 \mathrm{eV}^{20} 12.06 \mathrm{eV}^{21}$ and $15.6 \mathrm{eV}^{22}$ respectively. The ionization potential of $\mathrm{N}_{2}$ is higher than that of $\mathrm{CO}_{2}$, and $\mathrm{N}_{2}$ is the main component of air. Thus, compared with $\mathrm{CO}_{2}$, air is easier to breakdown and the breakdown voltage of air is lower.

Fig. 7 compares the $V-I$ characteristics of air and $\mathrm{CO}_{2}$ at different temperatures. Corona discharge currents of $\mathrm{CO}_{2}$ are constantly higher than that of air. At $350{ }^{\circ} \mathrm{C}$ and on the port

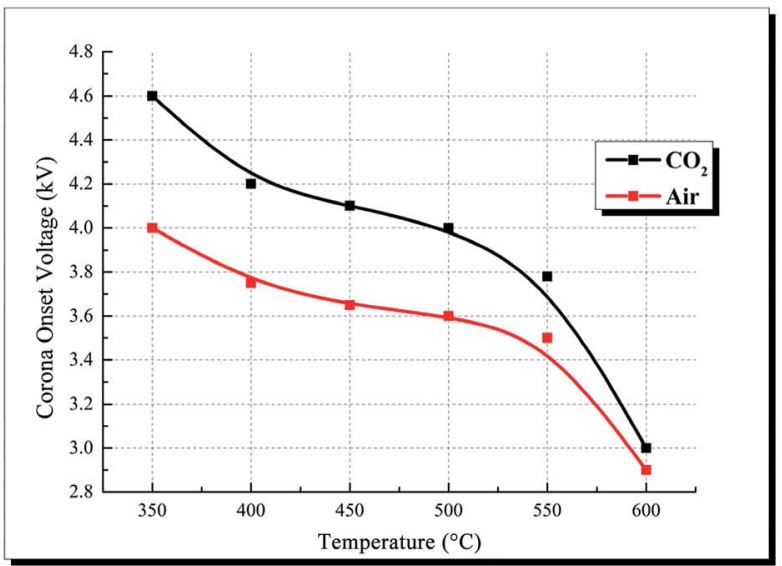

(a)

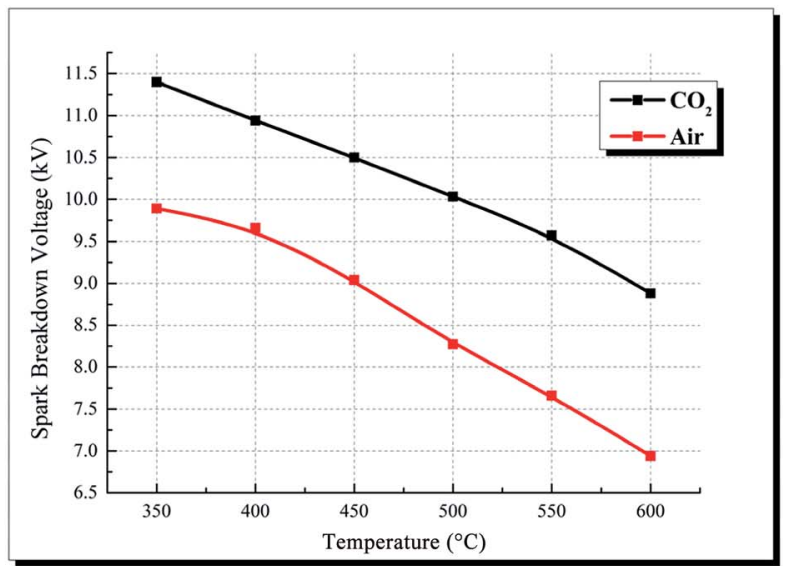

(b)

Fig. 6 Corona onset voltage and spark breakdown voltage vs. increasing ambient temperature in different atmospheres. (a) Corona onset voltage and (b) spark breakdown voltage.

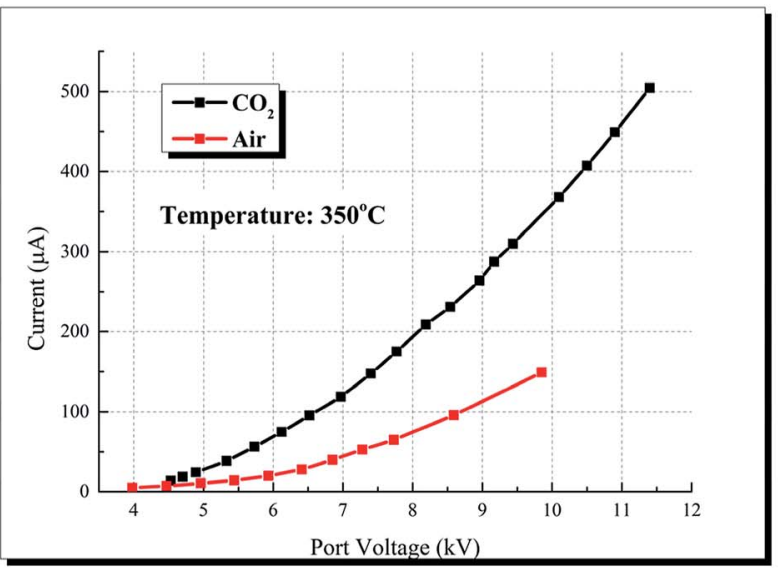

(a)

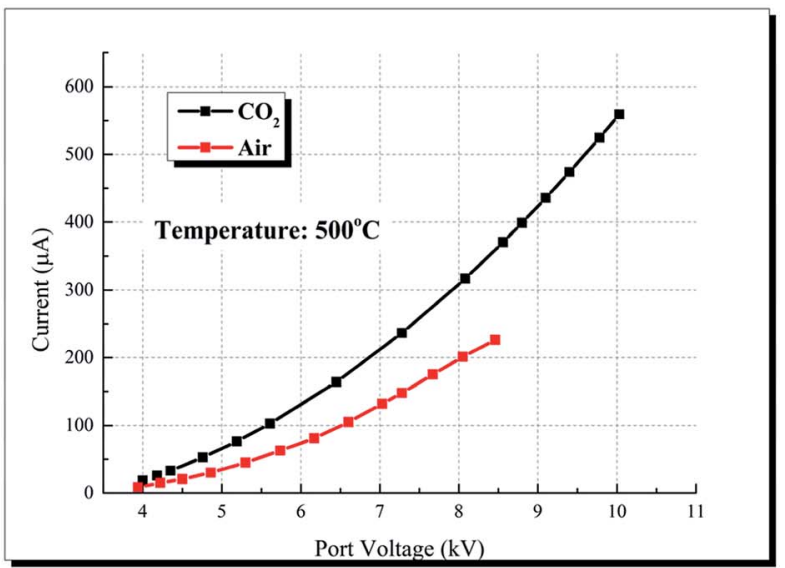

(b)

Fig. 7 Effect of gas media on corona discharge current at different temperature. (a) $350{ }^{\circ} \mathrm{C}$ and (b) $500{ }^{\circ} \mathrm{C}$. 
voltage of $7.75 \mathrm{kV}$, the corona discharge current of $\mathrm{CO}_{2}$ is $171 \mu \mathrm{A}$ while the current of air is $68 \mu \mathrm{A}$. Similarly, $\mathrm{Xiao}^{15}$ studied the discharge characteristics under air and $\mathrm{CO}_{2}$ gas media, and attributed the difference of currents to the electronegativity difference between air and $\mathrm{CO}_{2}$. However, Suriyawong ${ }^{26}$ studied the characteristics of electrostatic precipitation under $\mathrm{O}_{2}-\mathrm{CO}_{2}$ and $\mathrm{O}_{2}-\mathrm{N}_{2}$ atmosphere, and reported that the discharge current decreased with the increase of $\mathrm{CO}_{2}$ concentration under $\mathrm{O}_{2}-\mathrm{CO}_{2}$ atmosphere during positive discharge. The results of Suriyawong's work imply that $\mathrm{CO}_{2}$ is more difficult to be ionized compared to $\mathrm{O}_{2}$. However, apart from ionization, electronegativity plays an important role in discharge current during negative corona discharge. In air, $\mathrm{O}_{2}$ molecules may directly attach electrons to form $\mathrm{O}_{2}{ }^{-}$, and the required electron energy is $0.058 \mathrm{eV} ;^{15,21}$ in $\mathrm{CO}_{2}$, its molecules attach electrons through a two-step reaction (shown in eqn (7)), and the required electron energy is $3.85 \mathrm{eV} \cdot{ }^{\mathbf{1 5 , 2 0}}$ Gas molecules with high electronegativity (low required electron energy in the attachment reactions) can attach additional electrons at the drift region, thereby reducing the mean velocity of charges and the discharge current.

$$
\mathrm{CO}_{2}+\mathrm{e}^{-} \rightarrow \mathrm{CO}+\mathrm{O}+\mathrm{e}^{-}, \mathrm{O}+\mathrm{e}^{-} \rightarrow \mathrm{O}^{-}
$$

3.2.2 Comparison of electronegative gas media and nonelectronegative gas media. When electrons collide with gas molecules, some gas molecules can attach electrons to form negative ions, and these kinds of gas are referred as electronegative gas media, like air and $\mathrm{CO}_{2} \cdot{ }^{10,15}$ Other kinds of gas which cannot attach electrons, are referred as nonelectronegative gas media, like $\mathrm{H}_{2}, \mathrm{~N}_{2}$ and $\mathrm{CH}_{4} .^{10,15,23}$

The $V-I$ characteristics of a wire-cylinder configuration under $\mathrm{CO}_{2}$ gas medium at different temperatures are shown in Fig. 8 and photographs of the discharge are shown in Fig. 9. The corresponding port voltages and currents are listed in Table 1. When the temperature is within the range of $350-550{ }^{\circ} \mathrm{C}$, with the increase of output voltage, three types of discharge are observed. Photographs no. 1, no. 4 and no. 7 show cathode heads surrounded by faint light, depicting corona discharges before breakdown. After breakdown, a discontinuous optical

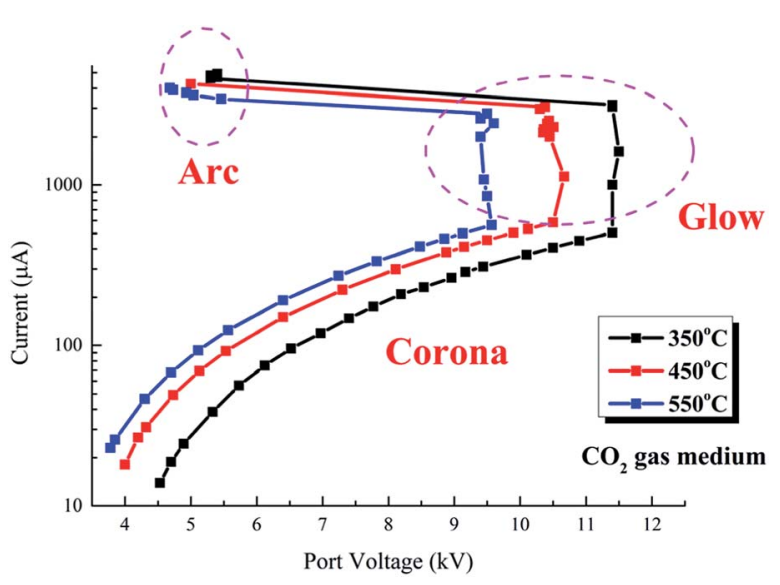

Fig. $8 \mathrm{~V}-\mathrm{l}$ characteristics of $\mathrm{CO}_{2}$ discharge at high temperatures.

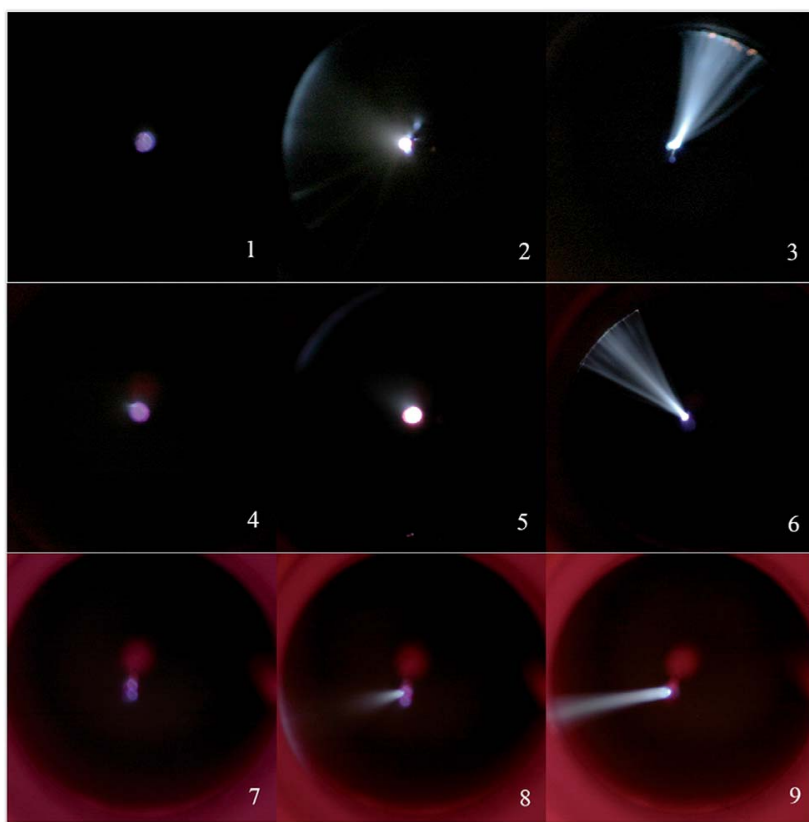

Fig. 9 Discharge photographs of $\mathrm{CO}_{2}$ discharge at high temperatures.

Table 1 The corresponding voltages and currents in Fig. 9

\begin{tabular}{|c|c|c|c|}
\hline & Corona & Glow & Arc \\
\hline $\begin{array}{l}\text { Temperature } \\
\left({ }^{\circ} \mathrm{C}\right)\end{array}$ & $\begin{array}{l}\text { Port voltage }(\mathrm{kV}) / \\
\text { current }(\mu \mathrm{A})(\mathrm{no} .)\end{array}$ & $\begin{array}{l}\text { Port voltage }(\mathrm{kV}) / \\
\text { current }(\mu \mathrm{A})(\text { no.) }\end{array}$ & $\begin{array}{l}\text { Port voltage }(\mathrm{kV}) / \\
\text { current }(\mu \mathrm{A})(\text { no.) }\end{array}$ \\
\hline 350 & $9.44 / 337.1(1)$ & $11.15 / 3078.6(2)$ & $5.4 / 4694(3)$ \\
\hline 450 & $9.15 / 395(4)$ & $10.38 / 3057(5)$ & $5 / 4262(6)$ \\
\hline 550 & $8.57 / 306.7(7)$ & $9 / 2195.4(8)$ & $4.68 / 4015(9)$ \\
\hline
\end{tabular}

channel connecting the two electrodes appears, indicating that the glow discharge begins, as shown in photographs no. 2 , no. 5 and no. 8. As the output voltage increases, the brightness of the luminous channel increases and the channel becomes continuous, which represents the arc discharge, as shown in photographs no. 3, no. 6 and no. 9. Corona refers to the phenomenon of partial discharge on the surface of charged body in gas

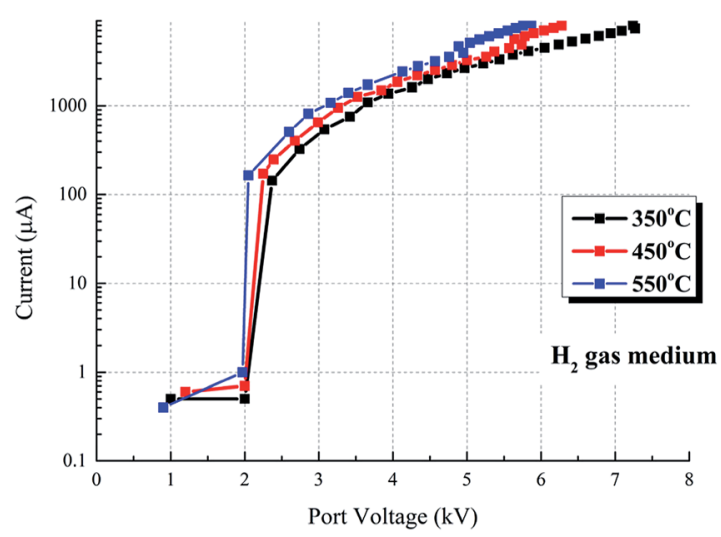

Fig. $10 \mathrm{~V}-\mathrm{I}$ characteristics of $\mathrm{H}_{2}$ discharge at high temperatures. 


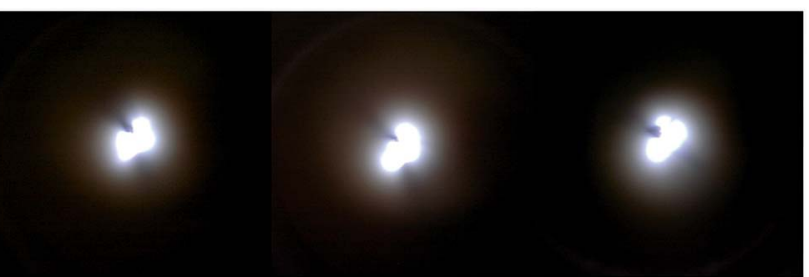

$350^{\circ} \mathrm{C}$

$400^{\circ} \mathrm{C}$

$450^{\circ} \mathrm{C}$

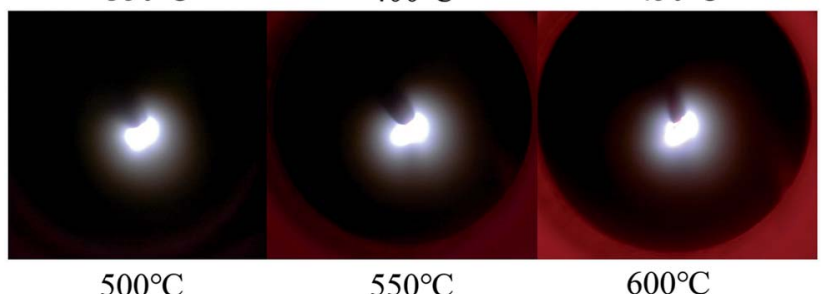

Fig. 11 Discharge photographs of $\mathrm{H}_{2}$ discharge at high temperatures.

medium. Glow discharge refers to the process during which the residual positive ions are accelerated in the electric field, obtaining enough kinetic energy to bombard the cathode, producing the secondary electrons, and the electrons will generate more charged particles through the avalanche to make the gas conductive. Arc discharge refers to the phenomenon of intense light and heat. As discussed above, corona discharge is partial discharge and occurs before gas breakdown. However,

Table 2 The corresponding voltages and currents in Fig. 11

\begin{tabular}{ll}
\hline Temperature $\left({ }^{\circ} \mathrm{C}\right)$ & Port voltage $(\mathrm{kV}) /$ current $(\mu \mathrm{A})$ \\
\hline 350 & $6.94 / 6520$ \\
400 & $6.38 / 7212$ \\
450 & $6.17 / 7479$ \\
500 & $5.97 / 7708$ \\
550 & $5.76 / 7972$ \\
600 & $5.57 / 8223$
\end{tabular}

glow discharge and arc discharge occur after gas breakdown. There are two main differences between the glow discharge and arc discharge: (1) glow discharge is caused by the secondary electrons emission, while arc discharge is caused by thermal ionization; (2) during glow discharge, the optical channel bridging the two electrodes is discontinuous, while during arc discharge, the optical channel is continuous.

The three discharge stages can be clearly distinguished in the $V-I$ characteristics, as shown in Fig. 8. Taking the $V-I$ characteristics at $550{ }^{\circ} \mathrm{C}$ as an example, with the port voltage increasing to $3.78 \mathrm{kV}$, corona discharge starts. Under this stage, as the port voltage increases, the currents increase and the corona currents are on the order of several tens to several hundred microamperes. As the port voltage increases to about $9.5 \mathrm{kV}$, spark breakdown occur and glow discharge starts. At the glow discharge stage, the port voltage remains almost unchanged with the increase of current. As the current increases to $3431 \mu \mathrm{A}$, the port voltage drops to $5.46 \mathrm{kV}$ immediately and arc discharge starts. At the arc stage, the port voltage decreases with increasing current.

The $V-I$ characteristics and photographs of the same device under $\mathrm{H}_{2}$ gas medium are shown in Fig. 10 and 11 respectively. The photographs (port voltages and currents are listed in Table 2) shown in Fig. 11 are different from these displayed in Fig. 9. Fig. 10 shows that the port voltage increases with the increase of current, suggesting that it is not arc discharge. Negative corona discharge does not occur in $\mathrm{H}_{2}{ }^{7}$ Thus, it is determined that the discharge shown in Fig. 11 is glow discharge. Taking the $V-I$ characteristics under $\mathrm{H}_{2}$ gas medium at $550{ }^{\circ} \mathrm{C}$ as an example, it begins to discharge at 2.05 $\mathrm{kV}$ and quickly breakdown, and the current reaches $164 \mu \mathrm{A}$ to form bright glow discharge. With the increase of port voltage, the discharge current increases greatly. When the port voltage increases to $5.87 \mathrm{kV}$, the discharge current increases to $8472 \mu \mathrm{A}$.

3.2.3 Negative DC discharge characteristics under $\mathrm{CO}$ gas medium. Fig. 12 illustrates the $V-I$ characteristics of $\mathrm{H}_{2}, \mathrm{CO}$, and $\mathrm{CO}_{2}$ at different temperatures. At the temperature of $20^{\circ} \mathrm{C}$

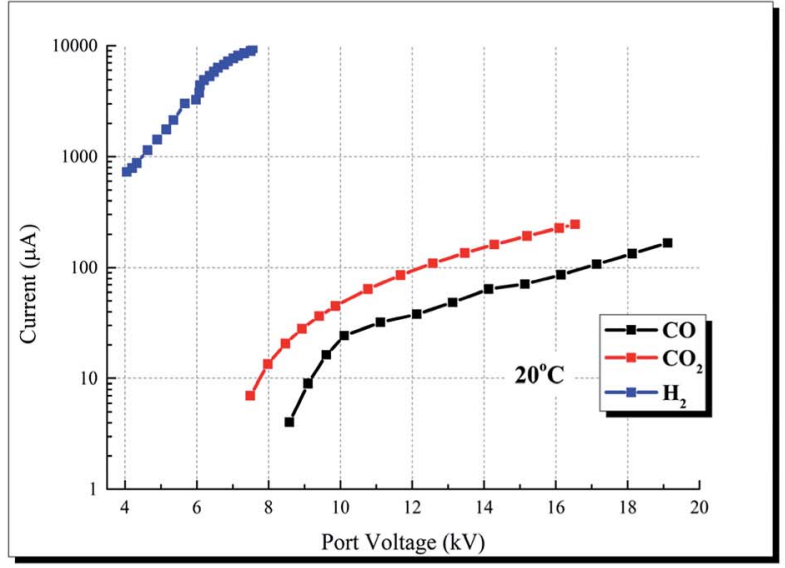

(a)

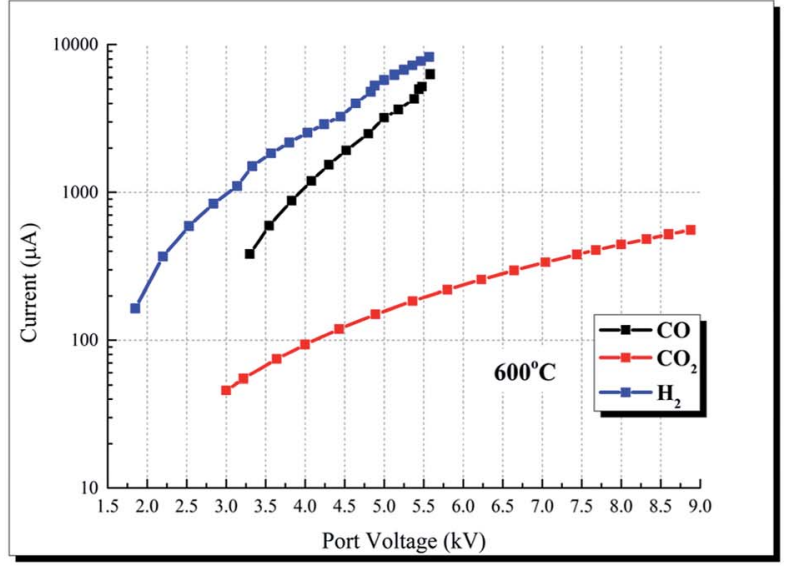

(b)

Fig. 12 Comparison of $\mathrm{CO}, \mathrm{H}_{2}$ and $\mathrm{CO}_{2}$ at different temperature: (a) $20^{\circ} \mathrm{C}$, (b) $600{ }^{\circ} \mathrm{C}$. 
and on the port voltage of $8.58 \mathrm{kV}$, the currents of $\mathrm{CO}_{2}$ and $\mathrm{CO}$ are $21 \mu \mathrm{A}$ and $4.03 \mu \mathrm{A}$, respectively. While the current of $\mathrm{H}_{2}$ is $9484 \mu \mathrm{A}$ on the port voltage of $7.56 \mathrm{kV}$. The results indicate that the capability of $\mathrm{CO}$ molecules to attach electrons is stronger than $\mathrm{CO}_{2}$ at $20^{\circ} \mathrm{C}$. However, at the temperature of $600{ }^{\circ} \mathrm{C}$ and on the port voltage of $4.05 \mathrm{kV}$, the currents of $\mathrm{H}_{2}, \mathrm{CO}_{2}$, and $\mathrm{CO}$ are 2558, 95 and $1190 \mu \mathrm{A}$, correspondingly. The results indicate that at high temperature, $\mathrm{CO}$ cannot attach electrons, and the discharge characteristics of $\mathrm{CO}$ are similar to the nonelectronegative gas media, such as $\mathrm{H}_{2}$ and $\mathrm{N}_{2}$. Table 3 lists certain experimental results of discharge currents in the gas media of $\mathrm{H}_{2}, \mathrm{CO}_{2}$, and $\mathrm{CO}$.

Table 3 Discharge currents

\begin{tabular}{|c|c|c|c|}
\hline & $\mathrm{CO}$ & $\mathrm{H}_{2}$ & $\mathrm{CO}_{2}$ \\
\hline $\begin{array}{l}\text { Temperature } \\
\left({ }^{\circ} \mathrm{C}\right)\end{array}$ & $\begin{array}{l}\text { Port voltage }(\mathrm{kV}) / \\
\text { current }(\mu \mathrm{A})\end{array}$ & $\begin{array}{l}\text { Port voltage }(\mathrm{kV}) / \\
\text { current }(\mu \mathrm{A})\end{array}$ & $\begin{array}{l}\text { Port voltage }(\mathrm{kV}) / \\
\text { current }(\mu \mathrm{A})\end{array}$ \\
\hline 20 & $8.6 / 4.2$ & $4.9 / 1427$ & $8.6 / 23$ \\
\hline 20 & $15.2 / 73$ & $7.56 / 9484$ & $15.2 / 193$ \\
\hline 600 & $3.5 / 580$ & $3.5 / 1720$ & $3.5 / 71$ \\
\hline 600 & $5.48 / 5200$ & $5.48 / 7800$ & $5.48 / 189$ \\
\hline
\end{tabular}

Table 4 Gas compositions after $\mathrm{CH}_{4}$ discharge process

\begin{tabular}{lc}
\hline Composition & Volume fraction (\%) \\
\hline $\mathrm{CH}_{4}$ & 98.44 \\
$\mathrm{H}_{2}$ & 1.35 \\
$\mathrm{C}_{2} \mathrm{H}_{4}$ & 0.12 \\
$\mathrm{C}_{2} \mathrm{H}_{6}$ & 0.09
\end{tabular}

Table 5 Corresponding currents in Fig. 13

\begin{tabular}{llll}
\hline Number & Time $(\mathrm{s})$ & Current $(\mu \mathrm{A})$ & Port voltage $(\mathrm{kV})$ \\
\hline 1 & 360 & 700 & 4.9 \\
2 & 610 & 1430 & 4.39 \\
3 & 790 & 1840 & 4.07 \\
4 & 820 & 770 & 4.9
\end{tabular}

\subsection{Effect of chemical reactions}

Table 4 displays the gas compositions after the $\mathrm{CH}_{4}$ discharge process when the temperature is $500{ }^{\circ} \mathrm{C}$, the output voltage is 20 $\mathrm{kV}$, and the residence time is approximately $8.73 \mathrm{~s}$. Gaseous products, such as $\mathrm{H}_{2}, \mathrm{C}_{2} \mathrm{H}_{4}$, and $\mathrm{C}_{2} \mathrm{H}_{6}$, and solid productions, i.e., carbon filaments, are produced through the $\mathrm{CH}_{4}$ discharge process

Fig. 13(b) presents the current curve at $20{ }^{\circ} \mathrm{C}$ and on the output voltage of $5.5 \mathrm{kV}$, and Fig. 13(a) depicts the discharge photographs of the current curve (time and currents are listed in Table 5). In the first photograph, glow discharge begins in the $\mathrm{CH}_{4}$ gas medium when the high voltage is applied to the discharge configuration. Carbon filaments and other gaseous products are produced when high energy electrons collide with $\mathrm{CH}_{4}$ molecules, and the discharge points move from the cathode to the endpoints of the carbon filaments. The second and third photographs show that the number and length of the carbon filaments increase simultaneously with the discharge and the corresponding currents. In the fourth photograph, the carbon filaments become unstable and collapse with the discharge current from the cathode when the length of the carbon filaments increases.

In addition to the collapse, another result for carbon filaments is depicted in Fig. 14 and Table 6. The carbon filaments reach the anode eventually when the length of the carbon

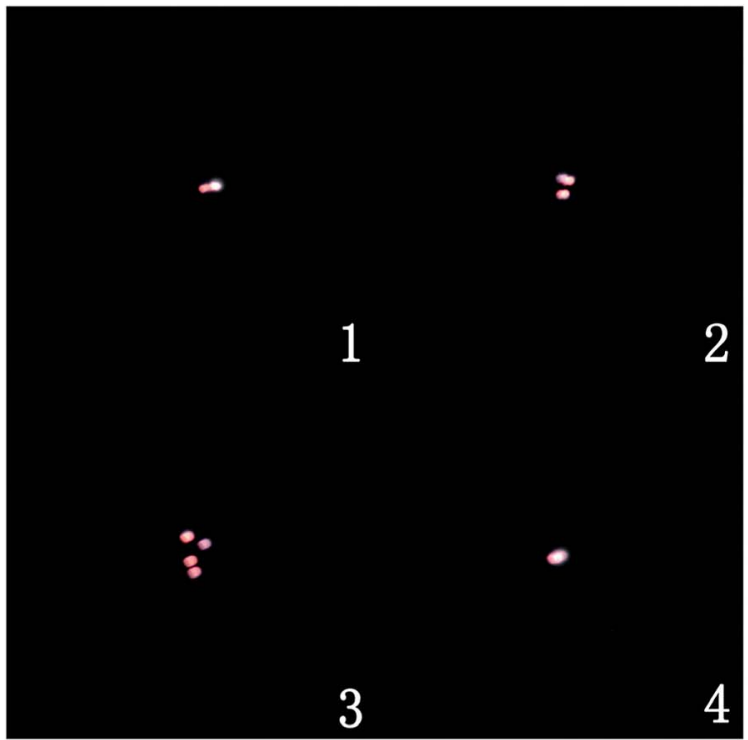

(a)

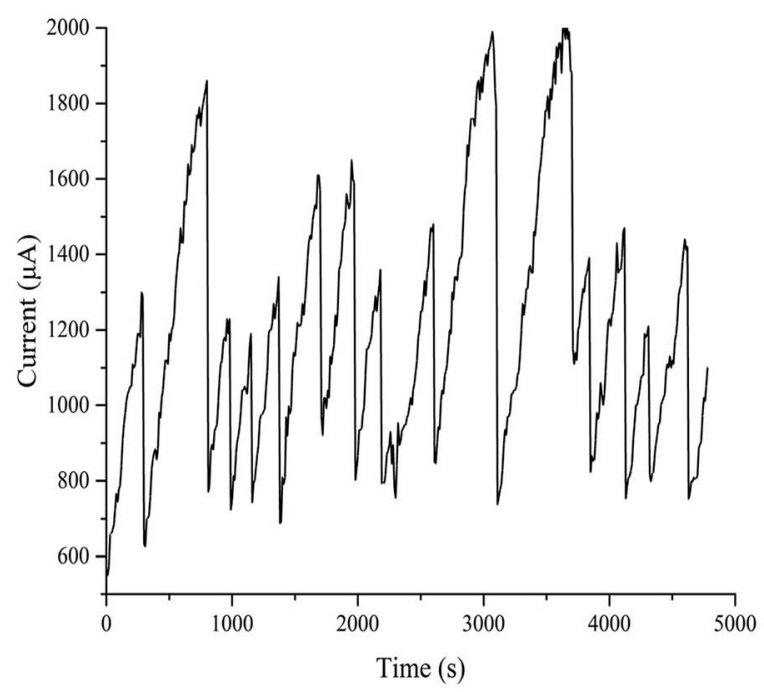

(b)

Fig. 13 (a) Discharge photographs and (b) its current curve at $20^{\circ} \mathrm{C}$ and on the output voltage of $5.5 \mathrm{kV}$. 


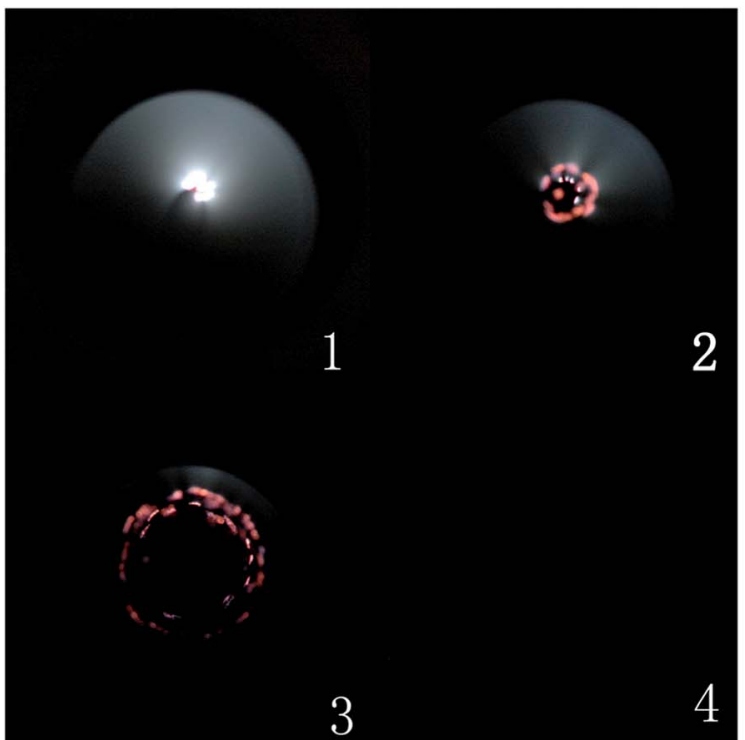

(a)

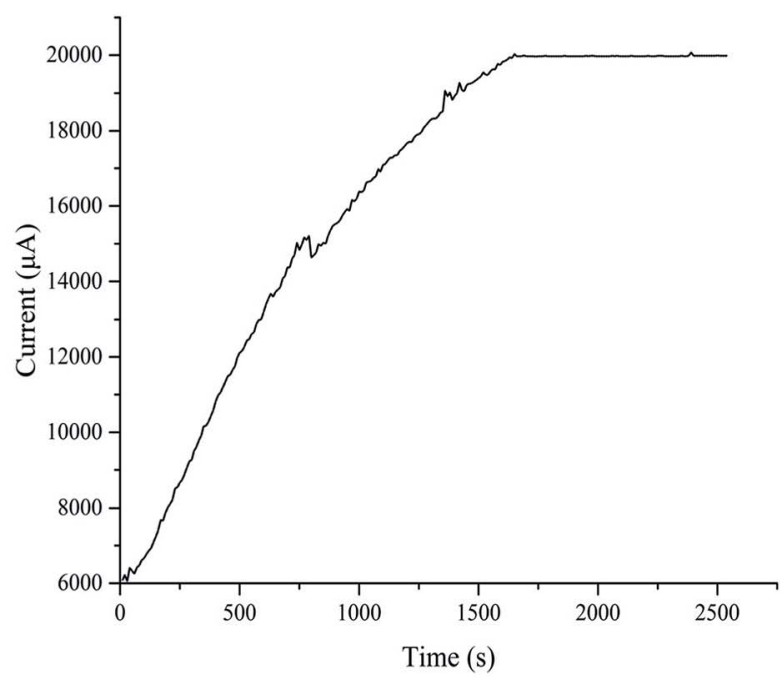

(b)

Fig. 14 (a) Discharge photographs and (b) its current curve at $20^{\circ} \mathrm{C}$ and on the output voltage of $20 \mathrm{kV}$.

filaments extends and connects the electrodes. At this moment, the port voltage decreases to $0.12 \mathrm{kV}$, and the output voltage decreases below $20 \mathrm{kV}$ because the maximum output current is $20 \mathrm{~mA}$.

Fig. 15 illustrates the comparison of the $V-I$ characteristics with the different voltage increasing rates. The red line represents the $V-I$ curve where the voltage increment is $0.5 \mathrm{kV}$, and each point takes $5 \mathrm{~min}$ to record, while the black line represents

Table 6 Corresponding currents in Fig. 14

\begin{tabular}{llll}
\hline Number & Time $(\mathrm{s})$ & Current $(\mu \mathrm{A})$ & Port voltage $(\mathrm{kV})$ \\
\hline 1 & 310 & 9500 & 12.6 \\
2 & 930 & 15740 & 7.53 \\
3 & 2090 & 19970 & 2.72 \\
4 & 2420 & 19980 & 0.12
\end{tabular}

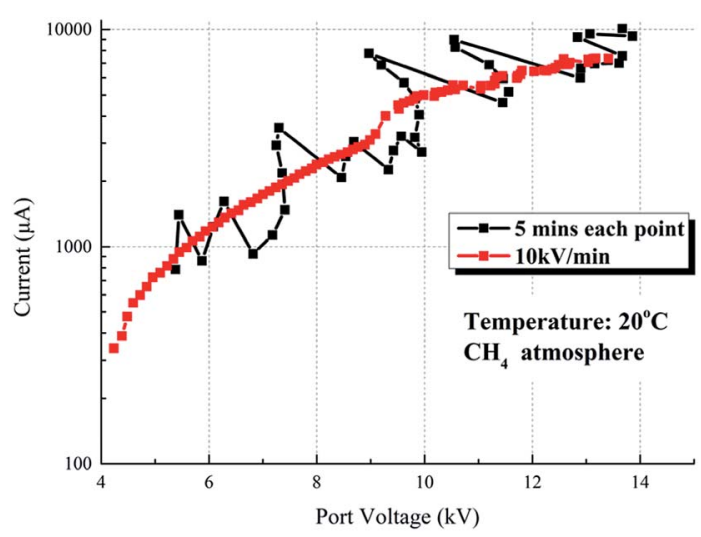

Fig. $15 \mathrm{~V}-/$ characteristics of $\mathrm{CH}_{4}$ at the temperature of $20^{\circ} \mathrm{C}$. the $V-I$ curve where the voltage increases at $10 \mathrm{kV} \min ^{-1}$ continuously. The trend and current value of the two lines are nearly coincidental with each other, except that the red line fluctuates more intense than the black line.

Fig. 16 compares the $V-I$ characteristics of $\mathrm{CH}_{4}$ and $\mathrm{H}_{2}$ at the temperature of $500{ }^{\circ} \mathrm{C}$. In $\mathrm{CH}_{4}$, the voltage increases at 10 $\mathrm{kV} \min ^{-1}$ continuously. The current value of these media is nearly identical, indicating that the discharge characteristics of $\mathrm{CH}_{4}$ are nearly similar to the $\mathrm{H}_{2}$ atmosphere.

These results indicate that chemical reactions affect discharge characteristics in two aspects: (1) the growth and collapse process of carbon filaments leads to the change in the discharge gap, thereby causing discharge current volatility, which means that the discharge current fluctuates violently during the discharge process; (2) in certain conditions, the growth of carbon filaments is stable and they reach the anode eventually, causing short circuit between the electrodes, leading to the termination of the discharge process. In addition to the

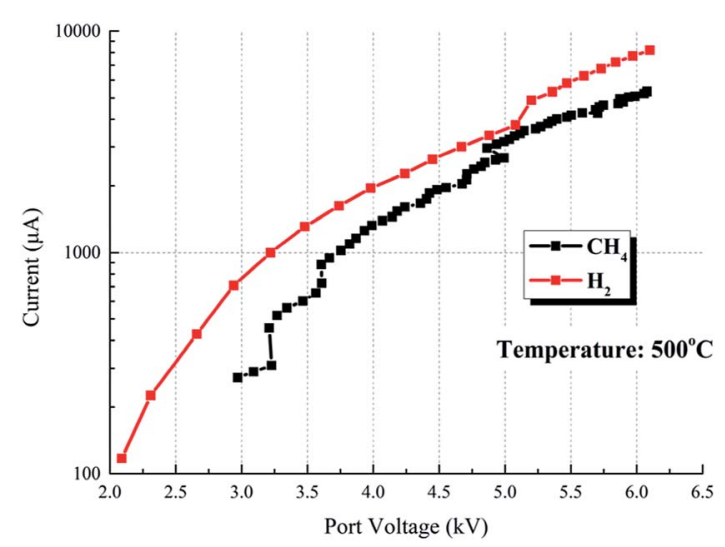

Fig. 16 Comparison of $\mathrm{CH}_{4}$ and $\mathrm{H}_{2}$ at the temperature of $500{ }^{\circ} \mathrm{C}$. 
two aspects, $\mathrm{CH}_{4}$ belongs to non-electronegative gas media, and its discharge characteristics are similar to those of $\mathrm{N}_{2}$ and $\mathrm{H}_{2}$.

In addition to $\mathrm{CH}_{4}$ atmosphere, chemical reactions and carbon generation occur during the CO discharge process. However, the two differences of carbon growth between $\mathrm{CO}$ and $\mathrm{CH}_{4}$ are as follows: (1) at $20^{\circ} \mathrm{C}$, carbon is produced during the $\mathrm{CH}_{4}$ discharge process, while carbon is not produced during the CO discharge process (carbon is produced during the $\mathrm{CO}$ discharge process when the temperature exceeds $350{ }^{\circ} \mathrm{C}$ ); (2) in $\mathrm{CH}_{4}$, carbon is produced in the structure of an umbrella around the cathode, while in CO, carbon is produced in powder form around the anode; therefore, neither the process of "growth and collapse" of carbon filaments nor the discharge current volatility occurs.

\section{Conclusion}

This work investigated the discharge characteristics of the main coal pyrolysis gas components $\left(\mathrm{CO}_{2}, \mathrm{H}_{2}, \mathrm{~N}_{2}, \mathrm{CH}_{4}, \mathrm{CO}\right)$ and air at 20-600 ${ }^{\circ} \mathrm{C}$. The following conclusions are drawn:

(1) With increasing temperature, corona onset voltage and spark breakdown voltage decrease, and spark breakdown voltage decreases more rapidly. The operational voltage range for corona discharge decreases from $8.5 \mathrm{kV}$ to $5.68 \mathrm{kV}$ as the temperature increases from $20{ }^{\circ} \mathrm{C}$ to $600{ }^{\circ} \mathrm{C}$.

(2) Discharge current increases as the temperature increases. The electron current ratio increases with the increase of temperature and applied voltage.

(3) Discharge current of $\mathrm{CO}_{2}$ is higher than that of air due to the difference of electronegativity. The corona onset voltages and spark breakdown voltages of $\mathrm{CO}_{2}$ are higher than those of air at the temperature range of $20-600{ }^{\circ} \mathrm{C}$.

(4) During $\mathrm{CO}_{2}$ discharge, with the increase of output voltage, three types of discharge are successively observed, namely corona, glow and arc. However, during $\mathrm{H}_{2}$ discharge, only glow discharge is observed.

(5) Temperatures significantly affect the capability of CO to attach electrons. At $20^{\circ} \mathrm{C}$, the discharge current is slightly lower in $\mathrm{CO}$ than in $\mathrm{CO}_{2}$. However, $\mathrm{CO}$ cannot attach electrons at 350$600{ }^{\circ} \mathrm{C}$, and the discharge current is similar to that of $\mathrm{H}_{2}$.

(6) Chemical reactions and carbon generation occur during the $\mathrm{CH}_{4}$ and $\mathrm{CO}$ discharge process. Chemical reaction has almost no effect on the discharge characteristics of CO. However, chemical reactions affect the discharge characteristics of $\mathrm{CH}_{4}$ in two aspects: (1) process of growth and collapse of carbon filaments leads to the discharge current volatility; (2) carbon filaments connecting two electrodes cause the discharge process to be terminated.

\section{Conflicts of interest}

There are no conflicts to declare.

\section{Abbreviations}

$r \quad$ Radial direction distance from the cathode, $\mathrm{m}$

$R \quad$ Radius of the anode tube, $\mathrm{m}$ radius of the cathode, $\mathrm{m}$

Effective length of the cathode, $m$

Electric field at a radius of $r, \mathrm{~V} \mathrm{~m}^{-1}$

Electric field at a radius of $r_{0}, \mathrm{~V} \mathrm{~m}^{-1}$

Saturation unipolar ion density, $\mathrm{A} \mathrm{s} \mathrm{m}^{-3}$

Dielectric constant, $\mathrm{F} \mathrm{m}^{-1}$

Port voltage applied to the electrode, $\mathrm{V}$

Discharge current, A

Saturation unipolar ion current, A

Electron current, A

Relative density

Relative molecular mass of the gas medium

Gas pressure of the experiments, $\mathrm{Pa}$

Standard atmospheric pressure, $P_{0}$ is $10325 \mathrm{~Pa}$

Temperature of the experiments, $\mathrm{K}$

Room temperature, $T_{0}$ is $298 \mathrm{~K}$

Residual current when gas is not discharged, A

Townsend first ionization coefficient, $\mathrm{m}^{-1}$

The distance between anode and cathode, $\mathrm{m}$

Townsend third ionization coefficient

The mean free path, $\mathrm{m}$

Ionization potential, $\mathrm{V}$

The mobility of negative ions, $\mathrm{m}^{2}\left(\mathrm{~V}^{-1} \mathrm{~s}^{-1}\right)$

Ion drift time, $\mathrm{s}$

\section{Acknowledgements}

This work was financially supported by the National Key R\&D Program of China (No. 2017YFB0602800 and No. 2016YFE0102500).

\section{Notes and references}

1 Q. Wang, Coal Staged Conversion Polygeneration Technology Combining with Pyrolysis and Combustion Processes, Springer International Publishing, 2017.

2 T. Melchior and R. Madlener, Economic evaluation of IGCC plants with hot gas cleaning, Appl. Energy, 2012, 97, 170-184.

3 X. Xu, X. Gao, P. Yan, W. Zhu, C. Zheng, Y. Wang, et al., Particle migration and collection in a high-temperature electrostatic precipitator, Sep. Purif. Technol., 2015, 143, 184-191.

4 G. Ahmadi and D. H. Smith, Gas flow and particle deposition in the hot-gas filter vessel of the Pinon Pine project, Powder Technol., 2002, 128, 1-10.

5 G. Xiao, X. Wang, J. Zhang, M. Ni, X. Gao, Z. Luo, et al., Granular bed filter: A promising technology for hot gas clean-up, Powder Technol., 2013, 244, 93-99.

6 P. Yan, C. Zheng, G. Xiao, X. Xu, X. Gao, Z. Luo, et al., Characteristics of negative DC corona discharge in a wireplate configuration at high temperatures, Sep. Purif. Technol., 2015, 139, 5-13.

7 X. Xu and D. Zhu, Gas Discharge Physics, Fudan University Press, 1996.

8 A. Villot, Y. F. J. Gonthier, E. Gonze and A. Bernis, Numerical Model of Current-Voltage Curve for the Wire-Cylinder 
Electrostatic Precipitators in Negative Voltage in the Presence of Nonpolar Gases, IEEE Trans. Plasma Sci., 2010, 38, 2031-2040.

9 A. Bologa, H. R. Paur, H. Seifert and K. Woletz, Influence of gas composition, temperature and pressure on corona discharge characteristics, International Journal of Plasma Environmental Science and Technology, 2011, 5, 110-116.

10 P. Yan, C. Zheng, W. Zhu, X. Xu, X. Gao, Z. Luo, et al., An experimental study on the effects of temperature and pressure on negative corona discharge in high-temperature ESPs, Appl. Energy, 2016, 164, 28-35.

11 X. Wang, M. Ni, G. Xiao, J. Zhang, X. Gao and K. Cen, An analytical method for DC negative corona discharge in a wire-cylinder device at high temperatures, J. Electrost., 2014, 72, 270-284.

12 Z. Gu, X. Xi, J. Yang and J. Xu, Properties of RE-W cathode and its application in electrostatic precipitation for high temperature gas clean-up, Fuel, 2012, 95, 648-654.

13 J. Xu, Z. Gu, X. Xi, J. Zhang and J. Liu, Loss mechanism and lifetime estimation of $\mathrm{Ce}-\mathrm{W}$ cathode in high temperature thermionic emission electrostatic precipitation, $J$. Electrost., 2014, 72, 336-341.

14 A. Villot, Y. Gonthier, E. Gonze, A. Bernis, S. Ravel, M. Grateau, et al., Separation of particles from syngas at high-temperatures with an electrostatic precipitator, Sep. Purif. Technol., 2012, 92, 181-190.

15 G. Xiao, X. Wang, J. Zhang, M. Ni, X. Gao and K. Cen, Characteristics of DC discharge in a wire-cylinder configuration at high ambient temperatures, J. Electrost., 2014, 72, 13-21.

16 G. Xiao, X. Wang, G. Yang, M. Ni, X. Gao and K. Cen, An experimental investigation of electrostatic precipitation in a wire-cylinder configuration at high temperatures, Powder Technol., 2015, 269, 166-177.

17 G. Xiao, X. Wang, J. Zhang, M. Ni, X. Gao and K. Cen, Current analysis of DC negative corona discharge in a wire-cylinder configuration at high ambient temperatures, J. Electrost., 2014, 72, 107-119.

18 G. V. Naidis, Simulation of streamer-induced pulsed discharges in atmospheric-pressure air, Eur. Phys. J.: Appl. Phys., 2009, 47, 22803.

19 R. S. Sigmond, Simple approximate treatment of unipolar space-charge-dominated coronas: The Warburg law and the saturation current, J. Appl. Phys., 1982, 53, 891-898.

20 Y. Itikawa, Cross Sections for Electron Collisions With Carbon Dioxide, J. Phys. Chem. Ref. Data, 2002, 31, 749.

21 Y. Itikawa, Cross Sections for Electron Collisions with Oxygen Molecules, J. Phys. Chem. Ref. Data, 2009, 38, 1.

22 Y. Itikawa, Cross Sections for Electron Collisions with Nitrogen Molecules, J. Phys. Chem. Ref. Data, 2006, 35, 31.

23 J. Yoon, M. Song, J. Han, S. H. Hwang, W. Chang, B. Lee, et al., Cross Sections for Electron Collisions with Hydrogen Molecules, J. Phys. Chem. Ref. Data, 2008, 37, 913.

24 L. G. Christophorou, R. A. Mathis, S. R. Hunter and J. G. Carter, Effect of temperature on the uniform field breakdown strength of electronegative gases, Gaseous Dielectrics $V$, 1988, 63, 52-59.

25 G. F. L. Ferreira, O. N. J. Oliveira and J. A. Giacometti, Pointto-plane corona: Current-voltage characteristics for positive and negative polarity with evidence of an electronic component, J. Appl. Phys., 1986, 59, 3045-3049.

26 A. Suriyawong, C. J. Hogan Jr, J. Jiang and P. Biswas, Charged fraction and electrostatic collection of ultrafine and submicrometer particles formed during O-CO coal combustion, Fuel, 2008, 87, 673-682. 